\title{
What Intercollegiate Athletics Coaches Wish Faculty Knew: Implications for Curriculum and Instruction
}

\author{
Thomas A. Raunig ${ }^{1} \&$ Porter E. Coggins, $\mathrm{III}^{2, *}$ \\ ${ }^{1}$ Division of Professional Studies, University of Providence, Great Falls, USA \\ ${ }^{2}$ Department of Professional Education, Bemidji State University, Bemidji, USA \\ *Correspondence: Department of Professional Education, Box \#35, Bemidji State University, 1500 Birchmont DR \\ NE, Bemidji, MN 56601, USA. Tel: 1-218-755-2720.
}

Received: February 12, 2018

Accepted: March 7, 2018 Online Published: March 19, 2018

doi:10.5430/jct.v7n1p111

URL: https://doi.org/10.5430/jct.v7n1p111

\begin{abstract}
Collegiate athletics coaches play a vital role in the lives of student-athletes and regularly interact with the members of their teams more than faculty given the nature of athletics practice schedules compared to academic class schedules. Although the primary purpose of university attendance at all universities is pursuit of academic degrees, student-athletes receive broad non-academic, life-skills oriented education from athletics coaches. Typically, teaching faculty at American colleges and universities hold terminal degrees in their fields, but unlike international universities, faculty in the U.S. are not required to have any particular training in pedagogy. Due to the enormous amount of time athletics coaches spend with student-athletes, coaches, by nature must be effective communicators, effective motivators, effective teachers, and effective ethical models for their student-athletes to a degree not necessary for faculty members. The purpose of this paper was to gather recommendations from coaches for faculty members regarding needs of student-athletes, and a comparison of the perception of student-athlete needs between coaches and faculty members. We employed a mixed methods convergent parallel design. We administered a questionnaire that included both an open-ended response section to what the respondent wished faculty knew with respect to student-athlete success, and three Likert scale questions related to confidence in what faculty knew or did with respect to student-athlete academic needs. Based on the thematic coding of the responses by coaches, and quantitative analysis of the Likert scale questions, recommendations for faculty regarding curriculum and instruction are given in the discussion section.
\end{abstract}

Keywords: undergraduate, intercollegiate athletics, curriculum, instruction

\section{Introduction}

\subsection{Problem Statement}

Do intercollegiate coaches have anything of value to share with faculty members in the broad domain of student academic success? If so, why should faculty listen? What can faculty learn from intercollegiate coaches regarding student academic success? In a seminal report in 1976, (and again in 2004) Tharp and Gallimore investigated and documented the coaching characteristics of legendary collegiate basketball coach John Wooden. Tharp and Gallimore analyzed Wooden's final season as a coach and noted 8 characteristics of Wooden's coaching style and considered the value of each for classroom practice. In particular, they noted the following characteristics and relevance for teaching (using their thematic categories): "Instructions, Hustles, Modeling, Praises, Scolds, Nonverbal rewards and punishments, Scold / reinstruction" (pp. 74-75). Kageyama $(2014,2015)$ has also noted important characteristics of both coach John Wooden and coach Pat Summitt with respect to value of those characteristics for teachers including praise and expectation (respectively). Several of the themes identified by coaches and faculty will be explored with implications for faculty in the discussion section below, along with relevant connections to the previous work by Tharp, Gallimore and Kageyma. Our present study is based on intercollegiate athletics coaches' direct, written recommendations for university faculty regarding support for student-athlete academic and athletic success, rather than an analysis of practice and game coaching observations and behaviors. How can the insights and characteristics inherent in coaching inform faculty to further support student-athletes? Further, in what ways do 
faculty perceptions of student-athlete academic needs differ from the perception of student-athlete needs for academic success of coaches? Intercollegiate athletics coaches in the United States have a great responsibility and exert a tremendous influence on the lives of student-athletes. Coaches of collegiate teams typically engage in greater contact with student-athletes than course instructors and hold more roles in the lives of student-athletes than is typical for university faculty. Intercollegiate coaches serve as recruiters meeting prospective team members and parents, serve as teachers instructing aspects of the sport to student-athletes, serve as ethical role models regarding conduct on and off the playing field, and serve as mentors to student-athletes. In addition, intercollegiate athletics coaches are bound by the governing body for their athletics program. At the top-most level, these bodies are the National Collegiate Athletic Association (NCAA) and the National Association of Intercollegiate Athletics (NAIA). These organizations dictate, among other issues, contact hours between coaches and student-athletes, and the context of contact. In season, when teams are holding scheduled practices and competitions, coaches typically meet with student-athletes for 1 - 3 hours a day for six days of the week, and a total of 20 hours a week for 24 weeks (NAIA, 2017; NCAA, 2017). The allowable practice hours are 8 when not in season (NAIA, 2017; NCAA 2017). This is in contrast with a typical 3 credit course in which the course instructor meets for just 3 hours per week over 15 weeks. Athletic coaches serve as teachers, expert communicators, motivators, role models, and mentors. Of course, to some degree, university faculty also assume these roles, but given the much greater contact time with student-athletes, the influence of coaches is greater. Although university faculty members typically are required to hold an advanced academic degree, they are not required to have any specialized training in pedagogy as Habilitation in many countries. The purpose of our research was to determine what advice intercollegiate athletic coaches have for university faculty regarding student-athlete success, and a comparison of awareness of student-athlete needs. We surveyed with a written questionnaire 35 intercollegiate athletic coaches employed full time as coaches and asked them what recommendations they would like to share with university faculty regarding support for student-athletes. To date, the scholarly literature has no record of athletic coaches' recommendations for university faculty regarding the success of student-athletes. Our study will help to reduce that gap in the literature. In addition, we surveyed 37 full time, tenure-track and tenured faculty members with the same written questionnaire in order to compare their responses with the recommendations of coaches.

\subsection{Significance of the Problem}

Intercollegiate athletic coaches can inform university faculty on the needs of student-athletes from the unique perspective coaches have due to the greater number of contact of contact hours with student-athletes compared to university faculty. Further, a comparison of the perspectives of student-athlete needs of faculty compared to coaches can offer conversation starting places to ensure that the unique needs of student-athletes are met for both academic and athletic performance goals.

\subsection{Purpose}

The purpose of this study was to both solicit recommendations from intercollegiate athletic coaches for university faculty related to student-athlete needs, and to compare perception of needs between university faculty and coaches.

\section{Methods}

\subsection{Methodology}

To adequately address our research questions, given below, we employed a mixed methods convergent parallel design (Mills \& Gay, 2016, p. 429). We used a convenient sample of both 35 full-time intercollegiate coaches and 37 full-time, tenured or tenure-track faculty. Coaches and faculty were employed at two schools, one in the Rocky Mountain region of the United States, and the other in the Great Lakes region of the United States. One school has a student body of approximately 950 students and is a member of the National Association of Intercollegiate Athletics (NAIA). This school sponsors 17 NAIA teams in their regional division. The other school has a student body of approximately 5,000 students and is a member of the National Collegiate Athletic Association (NCAA). This school sponsors 15 NCAA teams in their regional division with 2 teams participating in Division I, and 13 teams participating in Division II.

\subsection{Hypotheses}

There is a difference in the perception of student-athlete needs for academic success among university faculty compared to university intercollegiate athletic coaches. 


\subsection{Instrument}

We administered a survey with four questions to both university intercollegiate athletic coaches and university faculty. The first question was open-ended and written as "What do you wish your faculty colleagues knew, should keep in mind, and do to help student-athletes succeed academically?

The three Likert scale questions were as follows:

1. Most faculty members of this campus are aware of specific needs of student-athletes on your campus.

2. Most faculty members of this campus construct course assignments with specific needs of student-athletes in mind.

3. Most faculty members of this campus set expectations for student-athletes in equity and fairness (aka, reasonableness and just).

All three of the Likert scale questions used the same response directions:

"For each question below, please rate your confidence in the following questions using the scale below."

The scale was written as:

" 5 = Strongly Agree $/ 4$ = Agree $/ 3$ = Unsure $/ 2$ = Disagree $/ 1$ = Strongly Disagree".

All three of the Likert scale questions were written in a consistent way such that the responses along the spectrum from strongly agree to strongly disagree for each question resulted in response direction toward agree for positive responses to the questions and response direction toward disagree for negative responses to the questions.

\subsection{Procedures}

Institutional Review Board (IRB) approval was secured at the two small universities. Upon IRB approval at each university, all coaches were solicited to participate. Those interested in participation were read and signed an informed consent notifying them of their rights of confidentiality, anonymity, and the right to withdraw from the study at any time without repercussions. A convenient sample of university faculty was solicited to participate in the study. Those interested in participation were read and signed the informed consent notifying them of their rights of confidentiality, anonymity, and the right to withdraw from the study at any time without repercussions. Once informed consent was signed and received, the questionnaire was given to each participant. Upon completion of the questionnaire, all were scanned by the authors and distributed to all authors for analysis. The authors analyzed the open-ended question independently and independently identified emergent themes and coded the emergent themes. Once identification of themes and coding were completed, the themes were then distributed to all authors for discussion and interpretation of common themes and unusual responses. Responses that were illegible, unintelligible, or blank were discarded, but reported as such in the analysis. The three Likert scale responses were recorded in an Excel spreadsheet with the raw Likert numerical score. The Likert scale score was interpreted as ordinal data allowing nonparametric inferential statistics to be computed and interpreted. VassarStats (Lowry, 2018) was used for all quantitative analysis.

\subsection{Limitations}

The limitations of this study include the small sample size, the type of universities surveyed, the general region where the universities are geographically situated, and a convenient sample of participants.

\subsection{Assumptions}

We suspect that our results would be consistent with results from a much larger sample of regional universities and colleges that are not funnel schools for student-athletes to professional sports. We assume that our respondents understood the questions and answered truthfully. We assume intercollegiate coaches have a unique perspective on needs of student-athletes and valuable insights for faculty based on the extensive contact coaches have with student-athletes.

\section{Results}

\subsection{Emergent Themes}

The written responses to the open-ended question What do you wish your faculty colleagues knew, should keep in mind, and do to help student - athletes succeed academically? were analyzed for themes based on emergent keywords from the responses. The responses by coaches and faculty are given in Table 1 and Table 2, respectively. 


\subsection{Themes Identified by Coaches}

Table 1. Themes Identified from Responses of Coaches

\begin{tabular}{ll}
\hline Identified Themes & Count \\
\hline Time Commitment and Demands on Time & 13 \\
The importance of three-way Communication & 6 \\
The need for flexibility on teacher's part & 4 \\
How much stress is put upon athletes & 3 \\
Help student athlete's sooner. Don't be sink or swim & 4 \\
The importance of professors appearing approachable, willing to develop a & \\
relationship with the student athlete and be empathetic to athletes. & 4 \\
Professors should put the needs of the student first & 2 \\
Student Athletes are better students than non-athletes & 2 \\
Everything a coach does is for the benefit of the player & 2 \\
How hard it is for an athlete to maintain balance & 2 \\
The importance of setting class times up to not interfere with practice (have & \\
more early in the day) & 2 \\
Attend Student Athlete events an appear supportive & 2 \\
Appreciate Athletics & 2 \\
Availability of Tutors and Mentors & 2 \\
\hline
\end{tabular}

"Count" indicates the number of times a theme item was expressed in the open-ended question of the questionnaire.

\subsection{Themes Identified by Faculty}

Table 2. Themes Identified from Responses of Faculty

\begin{tabular}{ll}
\hline Identified Themes & Count \\
\hline Time Commitment and Demands on Time & 9 \\
The importance of three-way Communication & 7 \\
The need for flexibility on teacher's part & 6 \\
How much stress is put upon athletes & 1 \\
$\begin{array}{l}\text { Help student athlete's sooner. Don't be sink or swim } \\
\text { The importance of professors appearing approachable, willing to develop a }\end{array}$ & 1 \\
relationship with the student athlete and be empathetic to athletes. & 5 \\
$\begin{array}{l}\text { Professors should put the needs of the student first } \\
\text { Student Athletes are better students than non-athletes }\end{array}$ & 1 \\
$\begin{array}{l}\text { Everything a coach does is for the benefit of the player } \\
\text { How hard it is for an athlete to maintain balance }\end{array}$ & 6 \\
The importance of setting class times up to not interfere with practice (have & 1 \\
more early in the day) & 2 \\
$\begin{array}{l}\text { Design instruction that gives the student athlete the same learning } \\
\text { opportunities as other students. }\end{array}$ & 5 \\
$\begin{array}{l}\text { Availability of Tutors and Mentoring } \\
\text { Make the class schedule to fit athletes schedule }\end{array}$ & 3 \\
$\begin{array}{l}\text { Improve understanding of transfer and international student eligibility } \\
\text { Emphasize time management from early on }\end{array}$ & 1 \\
$\begin{array}{l}\text { Attend Student Athlete events an appear supportive } \\
\text { Appreciate athletics }\end{array}$ & 1 \\
$\begin{array}{l}\text { Be aware of the impact travel has on access to IT, Library, Labs, and other } \\
\text { resources }\end{array}$ & 1 \\
The coaches should be viewed as partners to help the student succeed & 1 \\
\hline
\end{tabular}

"Count" indicates the number of times a theme item was expressed in the open-ended question of the questionnaire. 


\section{Analysis of Quantitative Results}

\subsection{Question Score Box Plots}

The aggregate score of the three Likert scale questions (see section 2.4 above) was computed as the sum of the scores of each of the three questions for each respondent and represents an overall total measure of perceived confidence in faculty awareness and course parameters for student-athlete academic success among coaches and faculty members. Figure 1 and Figure 2 depict the aggregate and individual question scores for coaches and faculty.

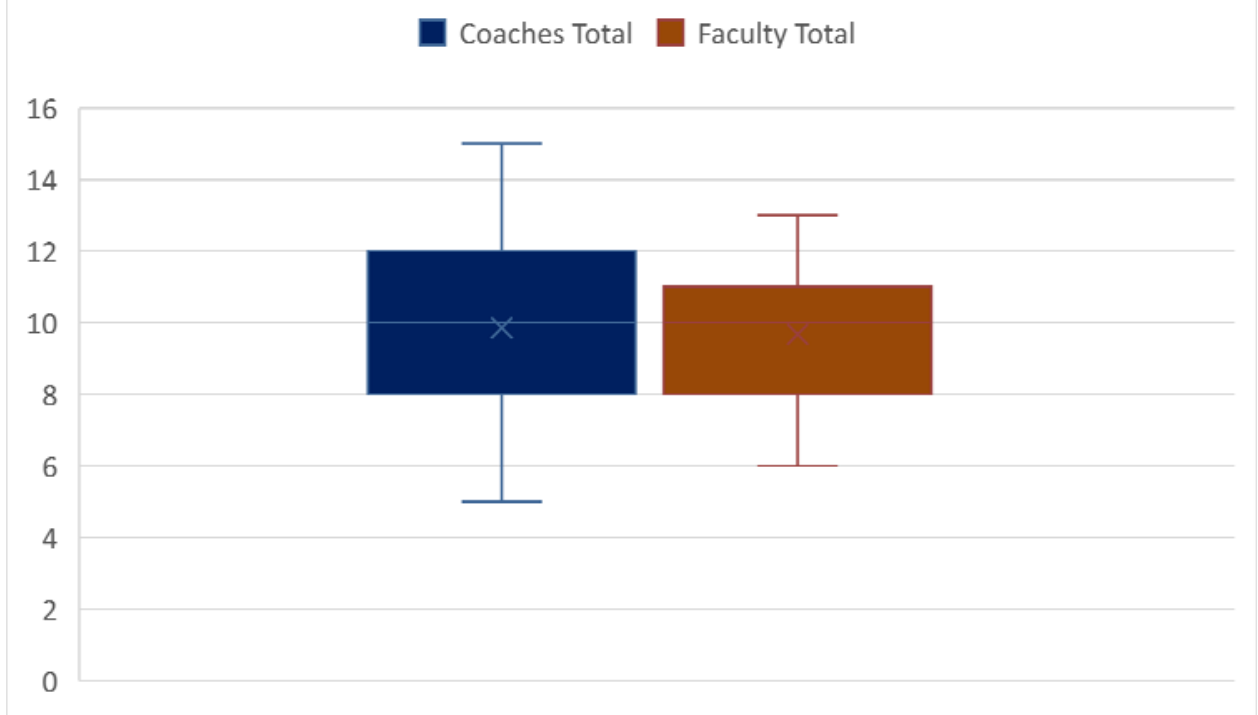

Figure 2. Comparison of Coaches Total Score to Faculty Total Score

Figure 2. Total Score Represents the Sum of the Questionnaire Scores for All Questions. Possible Range of the Total Score is 3 to 15

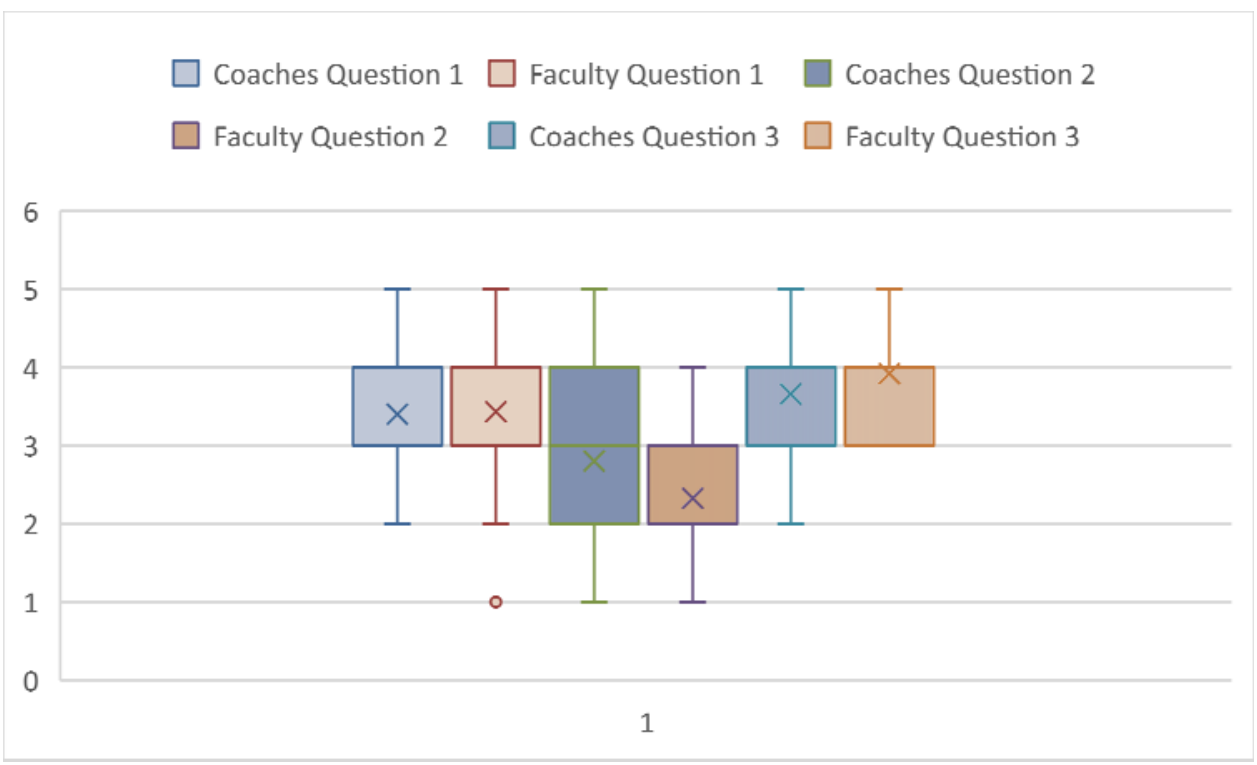

Figure 3. Comparison of Individual Question Scores of Coaches and Faculty

Figure 3. Individual Question Score Responses of Coaches Compared to Individual Question Score Responses of Faculty. Range of Possible Individual Scores on Each Question is 1 to 5 
Table 3. Count of Likert Scale Responses for Each Question

\begin{tabular}{|c|c|c|c|c|c|c|}
\hline & $\begin{array}{l}\text { For each question below, please rate your confidence in the } \\
\text { following questions using the scale below. } 5=\text { Strongly Agree } \\
/ 4=\text { Agree } / 3=\text { Unsure } / 2=\text { Disagree } / 1=\text { Strongly Disagree }\end{array}$ & 5 & 4 & 3 & 2 & 1 \\
\hline \multirow[t]{2}{*}{1} & Most faculty members of this campus are aware of specific needs & $\mathrm{C}-5$ & $\mathrm{C}-11$ & $\mathrm{C}-12$ & $\mathrm{C}-7$ & $\mathrm{C}-0$ \\
\hline & of student - athletes on your campus. & $\mathrm{F}-2$ & F-17 & $\mathrm{F}-14$ & $\mathrm{~F}-3$ & F-1 \\
\hline \multirow[t]{2}{*}{2} & Most faculty members of this campus construct course & $\mathrm{C}-2$ & $\mathrm{C}-8$ & $\mathrm{C}-11$ & C-9 & C-5 \\
\hline & assignments with specific needs of student - athletes in mind. & $\mathrm{F}-0$ & $\mathrm{~F}-4$ & F-11 & F-15 & F-7 \\
\hline \multirow[t]{2}{*}{3} & Most faculty members of this campus set expectations for student & $\mathrm{C}-5$ & $\mathrm{C}-17$ & C-9 & $\mathrm{C}-4$ & $\mathrm{C}-0$ \\
\hline & - athletes in equity and fairness (aka, reasonableness and just). & $\mathrm{F}-8$ & F-18 & $\mathrm{F}-11$ & $\mathrm{~F}-0$ & $\mathrm{~F}-0$ \\
\hline
\end{tabular}

"C-"represents the count of response for Likert scale category for coaches, "F-" represents the count of responses for Likert scale category for faculty.

\subsection{Correlation Matrices for Individual Questions}

Table 4. Correlation Matrix Responses to Three Questions by Coaches

\begin{tabular}{llll}
\hline $\mathrm{r}$ & Question 1 & Question 2 & Question 3 \\
\hline Question 1 & 1 & 0.633 & 0.580 \\
Question 2 & 0.633 & 1 & 0.554 \\
Question 3 & 0.580 & 0.554 & 1 \\
\hline
\end{tabular}

Table 5. Correlation Matrix Responses to Three Questions by Faculty

\begin{tabular}{llll}
\hline $\mathrm{r}$ & Question 1 & Question 2 & Question 3 \\
\hline Question 1 & 1 & 0.357 & 0.244 \\
Question 2 & 0.357 & 1 & 0.041 \\
Question 3 & 0.244 & 0.041 & 1 \\
\hline
\end{tabular}

\subsection{Statistical Inference Test Results of Coaches' Responses}

A Friedman chi-square test of independence of question responses of coaches to three questions was performed. There was sufficient evidence to reject the null hypothesis of no significant differences between question scores among coaches, $\chi^{2}(2)=15.61, p<0.0001$. A post-hoc Wilcoxon Signed-Rank test with Bonferroni correction was conducted for each pair of combinations of questions and indicated in Table 6.

Table 6. Post-Hoc Wilcoxon Signed-Rank test of Pairs of Coaches' Responses

\begin{tabular}{llll}
\hline Wilcoxon Signed-Ranks test & $\begin{array}{l}\text { Questions } \\
\mathbf{1} \text { and 2 }\end{array}$ & $\begin{array}{l}\text { Questions } \\
\mathbf{1} \text { and 3 }\end{array}$ & $\begin{array}{l}\text { Questions } \\
\text { 2 and 3 }\end{array}$ \\
\hline W & 180 & -73 & -315 \\
Z & 3.12 & -1.58 & -3.78 \\
$\begin{array}{l}\text { Two-tail p-value to significance alpha 0.05 with Bonferroni } \\
\text { correction to 0.0167 }\end{array}$ & & & \\
Effect Size & 0.0018 & 0.1141 & 0.0002 \\
\hline
\end{tabular}

\subsection{Statistical Inference Test Results of Faculty Responses}

A Friedman chi-square test of independence of question responses of faculty to three questions was performed. There was sufficient evidence to reject the null hypothesis of no significant differences between question scores among coaches, $\chi^{2}(2)=33.5, p<0.0001$. A post-hoc Wilcoxon Signed-Rank test with Bonferroni correction was conducted for each pair of combinations of questions and indicated in Table 7. 
Table 7. Post-Hoc Wilcoxon Signed-Rank test of Pairs of Faculty Responses

\begin{tabular}{llll}
\hline Wilcoxon Signed-Ranks test & Questions & $\begin{array}{l}\text { Questions } \\
\mathbf{1} \text { and 3 }\end{array}$ & $\begin{array}{l}\text { Questions } \\
\text { 2 and 3 }\end{array}$ \\
\hline $\mathrm{W}$ & 363 & -163 & -515 \\
$\mathrm{Z}$ & 4.35 & -2.64 & -4.81 \\
Two-tail p-value to significance alpha 0.05 with & & & \\
$\begin{array}{l}\text { Bonferroni correction to 0.0167 } \\
\text { Effect Size }\end{array}$ & 0.0001 & 0.0083 & 0.0001 \\
\hline
\end{tabular}

\subsection{Statistical Inference Test Comparing Aggregate Responses of Coaches to Aggregate Responses of Faculty}

A Mann-Whitney $U$ test indicated insufficient evidence to reject the null hypothesis of significant difference between the aggregate scores of coaches $(\mathrm{Mdn}=10)$ compared to the aggregate scores of faculty $(\mathrm{Mdn}=10), \mathrm{U}=667.5, \mathrm{Z}$ $=-0.22, \mathrm{p}(0.05)=0.8259, \mathrm{r}=-0.026$.

\subsection{Statistical Inference Test Results Comparing Individual Questions of Coaches to Faculty}

Table 8. Mann-Whitney U Test of Individual Questions Comparison of Coaches Compared to Faculty

\begin{tabular}{llll}
\hline Mann-Whitney U test & Questions & $\begin{array}{l}\text { Questions } \\
\mathbf{1} \text { and 3 }\end{array}$ & $\begin{array}{l}\text { Questions } \\
\text { 2 and 3 }\end{array}$ \\
\hline $\mathrm{U}$ & 621 & 804.5 & 554.5 \\
$\mathrm{Z}$ & 0.29 & -1.76 & 1.04 \\
Two-tail p-value to significance alpha 0.05 with & & & \\
Bonferroni correction to 0.0167 & 0.7718 & 0.078 & 0.2983 \\
Effect Size & 0.034 & -0.207 & 0.123 \\
\hline
\end{tabular}

\section{Discussion}

In considering the recommendations of coaches for faculty, and comparison of responses between coaches and faculty, it is important to put intercollegiate athletics into perspective in the broad domain of academics. Brand has argued for an integrated view of intercollegiate athletes and stated "The primary and defining feature of the Integrated View is that athletic programs are made part of the educational mission of the University. Although they are not part of the liberal-arts core, they play the same type of role as music and art, and perhaps business and journalism (2006, pp. 16-17), and "The value of hard work, striving for excellence, respect for others, sportsmanship and civility, team play, persistence, and resilience that underlie the ideal of sport should be brought into the developmental aspects of a college education affecting all students" (p. 19). In that light, Chaflin, Weight, Osborne, and Johnson quote former University of Michigan president, James Duderstadt “...college sports provide an opportunity for teaching people about character, motivation, endurance, loyalty, and the attainment of one's personal best- all great qualities of great value in citizens" (as cited in Chaflin, Weight, Osborne, \& Johnson, 2015, p. 3). Intercollegiate coaches have a unique perspective of student-athletes because of the greater contact time throughout the year with student-athletes.

\subsection{Implications of Emergent Themes}

The leading theme to emerge was that faculty need to be aware of time demands placed on student athletes by their sport. Faculty appeared to also be aware of the time demands, although not to as great of extent. Communication between the coach, athlete, and faculty member emerged as the second key theme. Athletes need to let the faculty member know when they are going to miss class, coaches also need to let faculty know too, but the faculty member needs to be clear with their communication on how they expect the student-athlete to accomplish what they need to in the class. The third most common theme was flexibility on the part of the faculty member. It was interesting that the faculty members surveyed referred to the need for flexibility more frequently than the coaches. That is logical, since faculty are directly impacted by their need to be flexible with student-athletes, whereas, coaches are not. Another theme that both coaches and faculty noted was the higher than average grade point average (gpa) and competitive nature and motivation of student-athletes compared to typical non-student-athletes.

\subsection{Time and Flexibility}

Because flexibility seems intricately connected to time, both of these themes are addressed here. Both coaches and faculty mentioned the time demand that intercollegiate athletics requires for student-athletes, and the need for 
flexibility on the part of faculty without sacrificing academic standards or expectations. In order to maximize and most efficiently make use of this valuable resource, coaches and faculty noted several suggestions to help student-athletes given their time constraints including letting student-athletes work early on assignments and allow make-up (coaches), give a course-long syllabus with all assignment / exam due dates (coaches), meet with student-athletes before and after travel or game days on content that will be covered during absence(s) (coaches), be available after class (coaches), be equitable regarding make-up and grading (coaches), consider course schedules with respect to practice (coaches), offer help sooner (coaches), know that sometimes student-athletes may be returning on Monday morning very early in the A.M. in the morning (coaches), student-athletes need priority registration (coaches). An important side effect of the issue of time noted by coaches was stress on student-athletes. Managing class assignments, preparing for exams, coordinating resources (textbooks, notes, technology, study sessions) in light of practice and game schedules can indeed take a toll on student-athletes, as it would anyone under the time pressures student-athletes live under both in-season and out. Taken together, these insights from coaches can help student-athletes make the most of their academics while participating in athletics with respect to the contractual time commitments that student-athletes are bound.

In contrast to insights and recommendations expressed by coaches, faculty stated several other recommendations that may help to make the most out of the limited time student-athletes have: college and athletics is like two full-time jobs; make reasonable attendance and homework policy accommodations (faculty), provide 'travel-friendly' assignments (faculty), make use of hybrid and asynchronous classes (faculty), consider rescheduling graded events if multiple students are traveling (faculty), absences due to athletics are excused by university policy and grades should not suffer because of excused absences for official travel (faculty), provide learning support for writing, taking notes, thinking outside the box in problem solving, tutoring (faculty), impact of travel on resources (faculty).

There were two points of interest within responses by coaches compared to responses by faculty in the domain of time. The first issue, that the faculty took note of, was that of time management and that the student-athletes need to learn to manage time, because "that is what employers expect", and the other issue of note was that on the one hand, coaches asked for class scheduling outside of practice times, while on the other hand, faculty asked that practices be held outside of class time. Of course, you can't have it both ways with class and practice schedules, and when multiple teams are scheduling practices for the limited facilities available, it becomes difficult to accommodate class schedules when sections are limited.

\subsection{Communication}

The second most common theme was related to the importance of communication between coaches, faculty, and student-athletes. Although Kavussanu, Boardley, Jutkiewica, Vincent, and Ring (2008, p. 401) noted the importance of communication between coaches and athletes, they did not address communication between faculty and athletes. The following points of consideration were noted by coaches regarding communication for faculty: let coaches know early regarding academic issues (coaches), be approachable (coaches), communicate expectations (coaches), keep in mind some students don't know as much as others in a subject (coaches), explain in multiple ways (coaches), develop rapport with student-athletes- asking about the game may motivate academically (coaches), get to know your students- you may change their lives and make the world a better place (coaches), be honest with student-athletes regarding improvement (coaches), establish a common language (coaches), clear delivery of the message (coaches).

Faculty made the following observations regarding communication: have open relationships with coaches so dialogue about student-athletes is easier to facilitate, coaches should be viewed as partners (faculty), clear expectations regarding assignments completion deadlines and extensions (faculty), make personal connections with student-athletes to understand issues they may face (faculty), appreciate cultural diversity and language of diversity (faculty).

While coaches did not express any aspects of communication failure with faculty: faculty did note communication failure from coaches with the statement: coaches and students don't communication in advance, faculty need schedules in advance for course planning (faculty), have coaches develop relationships with faculty (faculty).

\subsection{Grade Point Average, Competitive Nature and Motivation}

The NCAA and NAIA have stated policies on academic expectations of student-athletes. As such, student-athletes are expected to commit to their own academic success, as well as, their athletic success. Coaches noted that student-athletes have higher than average grade point averages (gpa) (coaches), that student-athletes are motivated academically contrary to many professors' beliefs, and do have an academics first priority (coaches), that student-athletes are competitive by nature and need to be challenged and receive instant feedback (coaches), that 
faculty should understand what motivates student-athletes to attend class (coaches), that faculty should keep the classroom engaging rather than straight lecture (coaches), mocking or belittling student-athlete's sport can have a detrimental effect on academic motivation (coaches).

Faculty also noted that student-athletes typically have a high gpa, but that faculty should ensure student-athletes are engaged in learning and should facilitate the same love of academics that student-athletes have for athletics (faculty), faculty failing to support or discourage / minimize student-athlete passion for sports or failing to accommodate or recognize pride in the classroom can negatively affect academic motivation (faculty).

The fact that coaches are generally liberal with their feedback to their student-athletes during practice, and sometimes so fast with it that the feedback can even hinder the student-athletes' ability to process what they have done, is much different than the approach taken by most professors. Some professors are inclined to be slow in providing feedback, which is not what the student athlete is used to. Whether these two different methods create dissonance on the part of the student athlete is beyond the scope of this study.

\subsection{Stress}

Surprisingly, stress was not high on the list of themes mentioned by coaches or faculty. However, the amount of stress put upon the student athlete was noted on three coaches' surveys and only one faculty survey. Those numbers were surprisingly low. Perhaps, and only conjecture, coaches and faculty felt that all college students feel a great deal of stress, so there was an assumption that stress comes with being a college student. Studies (Davoren \& Hwang, 2014; Demirel, 2016; Gilbert, Gilbert, \& Morawski, 2007; Rodriguez, 2014) indicate that being a student athlete is a factor in anxiety and depression among both American and international college students. For example, Demirel (2016) reported that student-athletes "had statistically significantly higher depression, and anxiety, and psychological stress points compared to non-athlete university students" (p. 9424). Davoren and Hwang (2014) reported student-athletes sought help less often than their non-athlete peers (63\% compared to 68\%), and that student-athletes are also less likely to report having a mental health issue, which could be the reason why coaches and faculty do not have a great deal of awareness of the problem. Interestingly, the literature on intercollegiate student-athletes and stress is quite sparse (as noted by both the authors of this paper and Demirel in 2016) and seems to correlate with the low mention of stress by coaches and faculty in the open-response section of the questionnaire instrument used in this survey. A study on what student-athletes wish their teachers knew is in progress and may illuminate this issue from the perspective of the student-athletes.

\subsection{Implications of Quantitative Results}

Of interest at first glance is the moderate to strong correlation between the responses of coaches to the three Likert scale questions. But, upon closer inspection, for both questions 1 and 2, a majority of coaches indicated they were either undecided or disagreed with the statement regarding their confidence that faculty were aware of specific needs of student-athletes ( $54 \%$ for question 1) or that course assignments were constructed with student-athletes in mind ( $71 \%$ for question 2 ). In contrast, only $37 \%$ of coaches surveyed were either undecided or disagreed with the statement regarding their confidence that faculty set fair expectations for student-athletes. Regarding question 1,37\% of coaches, compared to $24 \%$ of faculty, noted the time commitment student-athletes are under through participation as members of intercollegiate athletics teams. This seems consistent with the response of the majority of coaches for question 1, because time commitment is an important need required of student-athletes. If this need is unrecognized, then it is reasonable to assume course assignments may not take those needs into account via either alternative assignments, recognizing access to resources, or other necessities required for academic success, and this is consistent with the coaches' majority response to question 2, and consistent with the strong correlation between responses for questions 1 and 2 by coaches.

In contrast to responses by the coaches, the correlation between the faculty responses to the same three questions indicated a low correlation. That noted, faculty nearly split equally on question 1 between agree and strongly agree with all other response options. At face value, half of faculty did recognize the specific needs of student-athletes, and this is consistent with the open response question, where the majority of comments noted the time commitment/demands of time for student athletes ( $24 \%$ of faculty responses). Similarly, a majority of faculty noted confidence that colleagues set fair expectations for student-athletes. Although not directly asked or assessed on the instrument used, we suspect this is because faculty likely have a sense of fairness for all students without regard to any particular group of students. But, again, this is conjecture since it was not directly addressed in this study, but a reasonable interpretation. However, particularly interesting, and somewhat surprising was that the majority of faculty $(89 \%)$ indicated they were either undecided or disagreed with the statement regarding their confidence that faculty constructed course assignments with student-athletes in mind. This is surprising considering that half of the faculty 
(51\%) indicated confidence that colleagues were aware of the specific needs of student-athletes. This is especially puzzling when considering nearly one-quarter of faculty noted the time commitment required of student-athletes.

From a statistical significance standpoint, because there was insufficient evidence to reject the null hypothesis of no difference between faculty, we must interpret the lack of statistically different scores in terms of the counts of responses in each category and the qualitative responses of coaches and faculty. It is possible that a larger sample size of both coaches and faculty might have indicated statistically significant differences between these groups on these questions. It is also possible that a rephrasing of each of the three questions might have drawn out and more clearly pinpointed differences based on these three questions of awareness, assignment construction, and expectations. Further research should be conducted.

Based on the survey results, survey question \#2 had the greatest range of scores and lowest average rating. That question, (Most faculty members of this campus construct course assignments with specific needs of student-athletes in mind.) might indicate that faculty, on average, believe that athletes should be treated the same as any other student. While that makes sense, it often goes against university policies. For example, most colleges have a policy for excusing athletes from class for team travel to competitions. Professors are often given the option to either require the student to complete the classwork they are missing in advance or do so before a specific deadline after they return. It is somewhat puzzling that question \#3 (Most faculty members of this campus set expectations for student-athletes in equity and fairness.) is the highest rated. On the surface, the two would seem to go together, if \#2 was high, \#3 would be very similar. Upon examining the two questions more closely, it could be surmised that based on the findings from question \#3 that coaches and fellow faculty believe that faculty have the best intentions toward the student-athlete. However, based on the findings for question \# 2, there is something missing in the actual implementation process.

\subsection{Recommendations for Curriculum and Instruction}

Based on the above, there appear to be concreate steps faculty can take to support student-athlete success based on comments by coaches and faculty.

\subsubsection{Time}

Due to the time pressure that student-athletes face as noted by coaches (and faculty), it is important that faculty maximize learning opportunities for students through careful planning of assignments, resources, and assessments. Coaches mentioned the importance of a clear syllabus with due dates for the entire term. Coaches also noted that it was important to consider prior knowledge of students. This is important for course planning to ensure students have sufficient support in a timely manner to avoid falling behind early in the semester. Bain (2004) suggested that faculty consider using backward design (see Wiggins \& McTighe, for an up-to-date interpretation of this process) in the context of the big course questions "What big questions will my course help students answer..." (Bain, 2004, p. 50) that Wiggins and McTighe might consider as essential (Wiggins \& McTighe, 2005, p. 110). Wiggins and McTighe suggest that careful planning requires faculty to consider what students should be prepared to be assessed over. In 1993 Gardner suggested that assignments be constructed in several ways to allow students options for meeting a learning objective based on a student's intelligence strength and that “....assessment of intelligences can play a crucial role in curriculum development" (p. 27). Thus, paying attention to students' multiple intelligences for designing assignment options may help students ultimately make deep intellectual inroads into the course essential questions. QWith respect to crafting learning objectives, Anderson, et al. (2001) have developed a metrics of knowdedge domains crossed with an updated version of Bloom's original taxonomy of objectives. So, taking advantage of careful planning through backward design, relevant essential questions, consideration of assignments created in terms of multiple intelligences, and creating learning objectives in terms of Bloom's taxonomy can all be part of creating a meaningful classroom experience for student-athletes that can maximize learning under the considerable time constraints that intercollegiate student-athletes live under. Faculty noted the importance of being mindful of the impact on athletic travel with respect to resource availability, creating hybrid and asynchronous class components with "travel friendly" (faculty) assignments that can be completed while students are out of class due to competition. Careful planning on the part of faculty taking these points into consideration can help student-athletes successfully complete courses in season.

\subsubsection{Coaches Noted That Student-Athletes are Motivated to Learn}

Student-athletes are competitive by nature, and creating meaningful, active learning opportunities can capitalize on the natural drive that student-athletes' possess. To do this, Wiggins and McTighe (2005) suggest (among other things) the acronym "whereto" for "Helping students know Where the unit is going and What is expected? Help the teacher 
know Where the students are coming from (prior knowledge, interests?, Hook all students and Hold their interest?, Equip students, help them Experience key ideas and Explore the issues?, Provide opportunities to Rethink and Revise their understandings and work?, Allow students to Evaluate their work and its implications?, Be Tailored (personalized) to the different needs, interest, and abilities of learners?, Be Organized to maximize initial and sustained engagement as well as effective learning?" (p. 22). These suggestions are consistent with Gardner's point of using the intelligence strength of students as a motivator for tailored assignments, and the matrix of knowledge and cognitive domains in creating learning objectives outlined by Anderson et al. (2001). When students have an opportunity to choose assignment variations that lead to the same learning objective, they are more likely to engage. Coaches also recommended that student-athletes, by their competitive nature, can be motivated by being challenged, but with that said, to remember student-athletes also need timely feedback. Timely feedback is important if students are to make both connections and corrections in understanding. Faculty recognized that competitive grouping for assignments may also motivate students based on their naturally competitive nature. Both coaches and faculty mentioned the importance of communication. Learning objectives, academic support, motivation all depend on the ability of faculty to communicate effectively with student-athletes.

\subsubsection{Communicating}

How faculty communicate can affect what student-athletes hear, what they believe about their potential, and the extent that they can be motivated to reach academic learning objectives. Coaches asked that they be notified early about academic issues and be kept in the loop. As one coach put it "Teachers and coaches are part of the same team" (coach). Contrary to perceptions, coaches did express a strong interest in the academic success of their athletes. Faculty expressed the same feeling regarding communication with coaches. As part and prerequisite to keeping the three-way communication open, coaches recommended that faculty be approachable. Along this point, one coach stated, "nobody cares how much you [faculty] know until they know you care" (coach). Noddings (1995) advocated for consideration of care and themes of care "...implies a continuous search for competence" (p. 676) as a way to “...connect our students and our subjects to great existential questions." (p. 676) and "...connect us person-to-person" (p. 676). Although the context of teaching themes of care is in the domain of curriculum in Noddings' statements, if care isn't authentic at a personal level between faculty and student, then all other themes of care are simply smoke and mirrors. However, when considering communication as a tool for instruction, it is important to remember that communication comes in verbal and nonverbal forms. It is importnat that faculty consider not just what they say, but how they say it. The volume incontext, the emotive force, rate of interruption, rate of affirming, active listening, and rate of feedback are all important components of verbal communication which can be used to enhance communication between faculty and student-athletes. Body language can also affect communication. With respect to the simultenaity of both modes of communication in an exchange, Okoli and Okpara (2017) noted "Hence, the nonverbal messages, conscious or unconscious, that are being sent by the speaker through appearance, attitude, gesture, and dress, are crucial to the communication of ideas" (p. 151), and later conclude "Communication skill is as good as content knowledge in defining teaching effectiveness" (p. 153). Clarity of written communication should also be considered in the context of assignment, assessment, and feedback. Faculty who attend to the broad aspects of communication and awareness of how both verbal and nonverbal communication affect the reception will likely be more effective than those who do not attend to these aspects.

Praise is an important aspect of communication that can lead to academic success or failure depending on how it is used. Although Wooden used praise sparingly as a coach, Dweck has studied the important consequences of praise on motivation. In 2007 she summarized her research to date along with related research on mindset with respect to praise. She defines mindset as two mental-state beliefs on one's own, or other's beliefs about capabilities. A fixed mindset is one in which one believes that intellectual capacity is fixed in a way that the capacity or volume of a glass or cup is fixed by the dimensions of the vessle, and that if one is naturally intelligent, learning will come relatively easy with little to no effort, and when challenged with something hard, they tend to give up quickly believing they simply don't have the natural intelligence to understand. On the other hand, a growth mindset is the belief that intellectual capacity is flexible and able to expand and believe that "...effort is a positive thing.: It ignites their intelligence and causes it to grow. In the face of failure, these students escalate their efforts and look for new learning strategies" (2007, p. 36). She, and others, have studied mindest in the context of praise and found that the type of praise can have a significant affect on student assessment performance. Specifically, she found that praising students for intelligence solidified a fixed mindset in students while praising students for effort created a growth mindset in students. How can faculty capitalize on mindset for the academic success of students? First, consider assessment where students have the opportunity to reflect, reconsider, and reevaluate their work, and praise them for the effort along those lines. Second, refrain from praise that singles out innate or natural intelligence and set your students up 
for a successful run with statements like "Yes, this assignment may be hard and cause you some frustration, but I have given you all the tools you need to do well on it; you can do it! Don't give up!" and be available to support your students.

Deci (1971) investigated the effects of rewards on motivation, and after s series of experiments concluded "...that when verbal reinforcement and positive feedback are used as external rewards, the subjects' intrinsic motivation seems to increase relative to the non-rewarded subjects" (p. 114). With respect to communication and motivation, and noting the work of Dweck, this suggests that clear communication that encourages a growth mindest in the context of verbal reinforcement and positive feedback can have a positive effect on student-athletes meeting academic learning objectives. Knowing your students, as recommended by coaches in the questionnnaire is invaluable for appropriate, individual communication. Coaches and faculty also noted the importance of communciating expectations.

\subsubsection{Expectations}

The success of teams coached by John Wooden and Pat Summitt was in a large part due to their ability to make their expectations clear in communication with players. In the classroom, if students are unsure what is expected, students may be suprised by how they are assessed for competency. Rosenthal and Jacobsen studied the effects of expectation on assessment outcomes in the 1960s and 1970s. In their seminal work, they found that the expectation teachers have for students regardless of student background can have a positive effect on student learning in terms of assessment outcomes (Rosenthal and Jacobson, 1966; 1992). Faculty can capitalize on this by setting high expectations in courses and giving students the scaffoling that allows students to reach those expectations. Taking into consideration student-athlete time constraints, and effective communication, faculty can help ensure students have the support they need to meet high learning standards. High expectations do not mean unattainable, unrealistic expectations. When faculty believe student-athletes can meet a high level of academic attainment, and give them the tools to accomplish that, student-athletes will be more likely to meet those academic learning objectives than not.

\subsubsection{Assessing}

Assessing perfomance in competition is more straightfoward to guage than understanding in an academic sense because either the ball went in the goal, or it did not, either the pass was caught, or it was not, either the runner's time better than past performance, or it was not. On the other hand, understanding in an academic context can be trickier to measure if the learning objectives and assessment standards are not clearly communicated, sufficient resources in given time contraints are not provided, if instructors are unavailable to meet with students before or after travel to communicate assignment policy and parameters, students will likely struggle. To maximise student learning opportunities, faculty might need to consider constructing assignments from a backward design (Wiggins \& McTighe, 2005), construction of learning objectives based on the revised Bloom's of learning (Anderson, et al., 2001), considering a variety of assignment options that all lead to meeting a learning objective (Gardner, 1993), encourage a growth mindet (Dweck, 2007), and hold high expectations (Rosenthal \& Jacombson, 1966; 1993).

\section{Conclusion}

Intercollegiate athletics coaches and faculty from two regional, midsized and small universities participated in a survey by completing a written questionnaire with an open-ended question and three Likert scale questions. The questions were related to their recommendations for faculty members as to student-athlete success and their confidence in faculty awareness of the needs and how to meet the academic needs of student-athletes. Coaches and faculty noted that time, communication, flexibility, and the competitive nature of student athletes are factors that all may affect academic performance. They made recommendations that can be incorporated into course curriculum and effective teaching practice to ensure success of student-athletes. Intercollegiate athletics draws a great deal of attention, and scrutiny. One group of some of the top minds in the United States has made a consistent effort to improve intercollegiate athletics, that group is the Knight Commission. Since 1989 university presidents, former presidents, chancellors, former athletes, and others have come together to make suggestions in hopes of driving reforms to intercollegiate athletics. Thanks to the Knight Commission's advice athlete graduation rates have risen to near $80 \%$, there is more financial transparency in intercollegiate athletics, and there is a greater emphasis on student-athlete well-being, as well as, their educational experience (Knight Commission, 1991-2018; 2010). The Commission's big picture approach has yielded important changes, but has done so with very little faculty, coach, or student-athlete input. Our study, and others like it, serve as a stepping stone between the big picture policies and ideas of the Knight Commission, and the day to day interaction between faculty, coaches, and student-athletes. 


\section{Acknowledgements}

We thank the athletics coaches and faculty for participating in this study, and we thank the anonymous reviewers for their comments and suggestions for improvements to our manuscript.

\section{References}

Anderson, L. W., Krathwohl, D. R., Airasian, P. W., Cruikshank, K. A., Mayer, R. E., Pintrich, P. R.,... Whittrock, M.C. (2001). A taxonomy for learning, teaching, and assessing: A revision of Bloom's taxonomy of educational objectives. New York: NY: Longman.

Bain, K. (2004). What the best college teachers do. Cambridge, MA: Harvard University Press.

Brand, M. (2006). The role and value of intercollegiate athletics in universities. Journal of the Philosophy of Sport, 33(1), 9-20. https://doi.org/10.1080/00948705.2006.9714687

Chalfin, P. L., Weight, E., Osborne, B., \& Johnson, S. (2015). The value of intercollegiate athletics participation from the perspective of employers who target athletics. Journal of Issues in Intercollegiate Athletics, 8, 1-27.

Davoren, A. K., \& Hwang, S. (2014). Mind, body and sport: Depression and anxiety prevelance in student-athletes. Retrieved

from http://www.ncaa.org/sport-science-institute/mind-body-and-sport-depression-and-anxiety-prevalence-student-at hletes

Deci, E. I. (1971). Effects of externally mediated rewards on intrinsic motivation. Journal of Personality and Social Psychology, 18(1), 105-115. https://doi.org/10.1037/h0030644

Demirel, H. (2016). Have university sport students higher scores depression, anxiety, and psychological stress? International Jounral of Environmental \& Science Education, 11(16), 9422-9425.

Dweck, C. S. (2007). The perils and promises of praise. Educational Leadership. October 34-39.

Gardner, H. (1993). Multiple intelligences: The theory in practice. New York, NY: Basic Books.

Gilbert, J. N., Gilbert, W., \& Morawski, C. (2007). Coaching strategies for helping adolescent athletes cope with stress. JOPERD, 78(2), 24. https://doi.org/10.1080/07303084.2007.10597967

Hsu, A., \& Malkin, F. (2011). Shifting the focus from teaching to learning: Rethinking the role of the teacher educator. Contemporary Issues in Education Research, 4(12), 43-50. https://doi.org/10.19030/cier.v4i12.6661

Kageyama, N. (2014, October 4). What is more effective-praise or criticism? Retreived from https://bulletproofmusician.com/what-is-more-effective-praise-or-criticism/

Kageyama, N. (2015, February 22). The perils of aiming low: How our expectations can shape our students' learning \& $\quad$ performance. Retreived from https://bulletproofmusician.com/the-perils-of-aiming-low-how-our-expectations-can-shape-our-students-learnin g-performance/

Kavussanu, M., Boardley, I. D., Jutkiewicz, N., Vincent, S., \& Ring, C. (2008). Coaching efficacy and coaching effectiveness: Examining their preditors and coparing coaches' and athletes' reports. Applied Research, 22, 383-404. https://doi.org/10.1123/tsp.22.4.383

Knight Commission on Intercollegiate Athletics. (2010). Restoring the balance: Dollars, values, and the future of college $\quad$ sports. Retrieved from https://www.knightcommission.org/wp-content/uploads/2017/09/restoring-the-balance-0610-01.pdf

Knight Commission on Intercollegiate Athletics. Impact (1991-2018). Retrieved from https://www.knightcommission.org/impact/

National Association of Intercollegiate Athletics. (2017). Official \& policy handbook. (32nd ed.). Retrieved from http://www.naia.org/fls/27900//1NAIA/pubs/legislative/NAIA_Official_Handbook.pdf

National Collegiate Athletic Association. (2017). Bylaw Article 17 countable athletically related activities, 3-13. Retrieved from https://www.ncaa.org/sites/default/files/20-Hour-Rule-Document.pdf

Noddings, N. (1995). Teaching themes of care. Phi Delta Kappan, 76(9), 675-679.

Okoli, A. C., \& Okpara, M. (2017). Relating communication competence to teaching effectiveness: Implications for teacher education. Journal of Education and Practice, 8(3), 150-154. 
Rodriguez, A. (2014). International student-athletes and stress: Implications for American universities' administrators. Journal of Academic Administration in Higher Education, 10(2), 39-47.

Rosenthal, R., \& Jacobson, L. (1966). Teachers' expectancies: Determinants of pupils' IQ gains. Psychological Reports, 19, 115-118. https://doi.org/10.2466/pr0.1966.19.1.115

Rosenthal, R., \& Jacobson, L. (1992). Pygmalion in the classroom: Teacher expectations and pupils' intellectual development. (Expanded ed.). Williston, VT: Crown House Publishing Limited.

Tharp, R. G., \& Gallimore, R. (1976). Basketballs' John Wooden: What a coach can teach a teacher. Psychology Today, 9(8), 74-78.

Wiggins, G., \& McTighe, J. (2005). Understanding by design. (2nd ed.). Alexandria, VA: ASCD. 